\title{
LEGUMINOSAE ARBUSTIVAS E ARBÓREAS DA FLORESTA ATLÂNTICA do Parque Nacional do Itatiaia, sudeste do Brasil: PADRÕES DE DISTRIBUIÇÃo ${ }^{1}$
}

Marli Pires Morim ${ }^{2}$

\section{RESUMO}

(Leguminosae arbustivas e arbóreas da floresta atlântica do Parque Nacional do Itatiaia, sudeste do Brasil: padrões de distribuição) O PARNA Itatiaia, com 28.155,97ha, localiza-se na Serra da Mantiqueira (22 $15^{\prime}$ e $22^{\circ} 30^{\prime} \mathrm{S} ; 44^{\circ} 30^{\prime} \mathrm{e} 44^{\circ} 45^{\prime} \mathrm{W}$ ) no sudeste do Brasil. Leguminosae é uma das famílias com maior riqueza de espécies na composição e estrutura florestal. O principal objetivo deste trabalho foi identificar os padrões de distribuição geográfica de 48 táxons de Leguminosae presentes na formação florestal do PARNA. A metodologia abrangeu pesquisas bibliográficas, excursões e consultas a herbários. Foram reconhecidos os seguintes padrões de distribuição: Neotropical (9 spp.), América do Sul ocidental-centro-oriental (5 spp.), Brasil centro-oriental (10 spp.), Brasil atlântico nordeste-sudeste-sul ( 9 spp.), Brasil atlântico sudeste-sul (5 spp.) e Brasil atlântico sudeste (10 spp.). Os táxons, quanto à preferência de hábitat, foram tratados também como elementos florísticos generalistas (56\%) e como especialistas do Domínio Atlântico (44\%). No domínio atlântico as espécies predominam nas floresta ombrófila densa e floresta estacional semidecidual, ocorrendo também nas restingas e na floresta de araucária.

Palavras-chave: Leguminosae, Parque Nacional do Itatiaia, Floresta Atlântica, padrões de distribuição.

\section{Abstract}

(Woody Leguminosae in the Atlantic Forest of the Itatiaia National Park, southeastern Brazil: distribution patterns) The Itatiaia National Park, with an area of $28,155.97$ ha, is located in the Serra da Mantiqueira Range $\left(22^{\circ} 15^{\prime} \mathrm{e} 22^{\circ} 30^{\prime} \mathrm{S} ; 4^{\circ} 30^{\prime} \mathrm{e} 44^{\circ} 45^{\prime} \mathrm{W}\right.$ ) of southeastern Brazil. Leguminosae is one of the most species-rich families here, contributing to the composition and structure of the forest. The aim of this work was to identify the geographical distribution patterns of 48 taxons of Leguminosae present in the forests of this National Park. Methodology included a literature survey, field trips and herbaria consultation. The following distribution patterns were recognized: Neotropical (9 spp.), western-central-eastern South America (5 spp.), centraleastern Brazil (10 spp.), northeastern-southeastern-southern atlantic Brazil (9 spp.), southeastern-southern atlantic Brazil (5 spp.) and southeastern atlantic Brazil (10 spp.). As for habitat preference, the taxons were classified as generalists (56\%) or as specialists of the atlantic domain (44\%). In the Atlantic Domain, the species are found mainly in the ombrophylous dense forest and in the semideciduous forest and occur also in restingas and araucaria forest.

Key-words: Leguminosae, Itatiaia National Park, Atlantic forest, distribution patterns.

\section{INTRODUÇ̃̃o}

Leguminosae é a terceira maior família de angiospermas e, atualmente, são estimados 727 gêneros e 19.325 espécies que se difundem nos diversos ecossistemas do mundo (Lewis et al. 2005). A região neotropical representa um significativo centro de endemismo da família, na qual 100 gêneros e 2.500 espécies têm seus limites de distribuição circunscritos a esta faixa (Lavin 1994). Para o Brasil foi avaliado o total de 178 gêneros e 1.550 espécies (Barroso et al. 1984).
As Leguminosae no contexto da floresta atlântica representam uma das famílias de valores expressivos de riqueza e também de diversidade taxonômica. No sudeste brasileiro os estudos realizados em um trecho de floresta ombrófila densa da Serra do Mar, Serra de Macaé, mostraram a relevância deste complexo montanhoso como um expressivo núcleo de distribuição de Leguminosae (Lima et al. 1994;Lima et al. 1997). Consultando-se os dados sobre a distribuição geográfica das Leguminosae da Serra de Macaé (Lima et al.

Artigo recebido em 11/2004. Aceito para publicação em 12/2005.

${ }^{1}$ Parte de tese de doutorado orientada por Dra.Graziela Maciel Barroso no Programa de Pós-Graduação em Ciências Biológicas (Botânica) do Museu Nacional/UFRJ, Rio de Janeiro, RJ, Brasil.

${ }^{2}$ Instituto de Pesquisas Jardim Botânico do Rio de Janeiro, Rua Pacheco Leão 915, CEP 22460-030, Rio de Janeiro, RJ, Brasil. mpires@jbrj.gov.br 
1994), observa-se ainda que a Serra da Mantiqueira é também uma área relevante de ocorrência para Leguminosae.

O Maciço do Itatiaia, remanescente de floresta atlântica importante da Serra da Mantiqueira, desde as primeiras visitas dos naturalistas M. H. Wawra von Fernsee e SaintHilaire (Dusén 1903, Brade 1956) sempre foi destacado como uma região de extremo potencial à investigação científica, motivo principal de sua criação como o primeiro Parque Nacional do Brasil, em 1937. Inúmeros foram os pesquisadores que visitaram e desenvolveram pesquisas na região. As descrições de espécies da flora local (Dusen 1903, 1955) e o estudo sobre a flora do Itatiaia (Brade 1956) são trabalhos que, entre outros, ressaltam a exuberância da região nos mais distintos aspectos. Brade (1956) apresentou uma abordagem sobre a estrutura regional da flora, sua provável origem e seus elementos florísticos. Os estudos sobre a origem da flora do Itatiaia e suas conecções biogeográficas prosseguem em investigações (Safford 1999 a, b). Dentre a coletânea de trabalhos sobre a flora do Parque destaca-se, principalmente, a região do Planalto que, recentemente, foi estudada em seus aspectos de estrutura, dinâmica e biogeografia (Ribeiro \& Medina 2002). A composição florística da formação florestal, principalmente em relação as espécies arbóreas, é, entretanto, muito pouco conhecida.

O Programa Mata Atlântica do Instituto de Pesquisas Jardim Botânico do Rio de Janeiro, na década de 90, iniciou um levantamento florístico e fitossociológico em um trecho de mata na formação florestal do Parque Nacional do Itatiaia. Os dados e resultados obtidos, entre outros aspectos, evidenciaram a importância da família Leguminosae na composição e estrutura da formação florestal atlântica do Parque como o terceiro grupo com maior riqueza de espécies (Guedes-Bruni 1998). No inventário realizado para as Leguminosae da mata atlântica do estado do Rio de Janeiro foi demonstrado que $45 \%$ do total dos gêneros e $28 \%$ do montante de espécies estão presentes na flora do Itatiaia (Lima 2000).

O tratamento florísitico e taxonômico dos táxons arbustivos e arbóreos de Leguminosae do Parque Nacional do Itatiaia resultou em um total de 50 espécies (Morim 2002) e propiciou, a partir da consulta as revisões de gêneros e em herbários, a reunião de um conjunto de informações sobre as amplitudes geográficas e a ocorrência das espécies, por vezes, também em outras formações vegetacionais.

Neste contexto, o presente trabalho tem como objetivo estabelecer os padrões de distribuição geográfica de 48 táxons, específicos e infra-específicos de Legumin osae, que ocorrem na formação florestal atlântica do Parque Nacional do Itatiaia. Nos padrões estabelecidos foram evidenciadas também outras formações vegetacionais de ocorrência dos táxons. A partir desta análise, as espécies são identificadas como elementos florísticos generalistas ou especialistas em relação ao Domínio Atlântico. O conjunto dos resultados obtidos busca subsidiar futuros trabalhos sobre padrões de distribuição de Leguminosae e, também, associado a estudos similares em outras famílias botânicas de relevância na composição da flora da região, contribuir no avanço do conhecimento sobre os padrões de distribuição da flora do Parque Nacional do Itatiaia.

\section{Material e Métodos}

\section{Coleta de dados}

Os procedimentos metodológicos abrangeram pesquisas bibliográficas sobre os táxons estudados e sobre o Parque Nacional do Itatiaia (PARNA Itatiaia). O registro de ocorrência das espécies foi obtido nas excursões de campo realizadas, principalmente, no período de 1998 a 2001, e através de consulta aos acervos de herbários.

Os espécimes foram coletados em área de amostragem localizada às margens do rio Campo Belo em uma cota de 900 metros de altitude, onde foi realizado, pela equipe do Programa Mata Atlântica/JBRJ, o inventário 
fitossociológico. A unidade amostral foi implantada adotando-se o método de amostragem de parcela e totalizou 1 hectare de mata em bom estado de conservação (Guedes-Bruni 1998). O diâmetro à altura do peito (DAP), igual ou maior que $5 \mathrm{~cm}$, foi o critério utilizado para a inclusão dos indivíduos no tratamento fitossociológico e para as coletas das amostras, seguidas de anotações sobre os caracteres vegetativos e/ou reprodutivos. Além dessa amostragem foram realizadas caminhadas livres, sem a demarcação prévia de trilhas, objetivando-se o reconhecimento e a coleta de espécimes de Leguminosae que não foram incluídas no levantamento fitossociológico. As caminhadas livres foram feitas em diferentes trechos da formação florestal, situados em altitudes compreendidas em uma faixa, aproximadamente, entre 600 a 2.000 metros, e priorizaram coletas de indivíduos em fases de floração e/ou frutificação. As amostras foram herborizadas de acordo com os procedimentos descritos em Guedes-Bruni et al. (2002) e depositadas no herbário do Instituto de Pesquisas Jardim Botânico do Rio de Janeiro (RB).

Os táxons Caesalpinioideae, Mimosoideae e Papilionoideae foram tratados como subfamílias subordinadas a Leguminosae. As análises filogenéticas têm demonstrado que Leguminosae é uma família monofilética (Wojciechowski 2003, Wojciechowski et al. 2004, Lewis et al. 2005) e, com base nestas evidências, esta é a classificação sistemática que tem sido ratificada (Lewis \& Schire 2003).

A identificação taxonômica procedeu-se a partir de consulta às revisões de gêneros, concernentes aos táxons abordados, aliada ao exame de material de herbário.

Os dados sobre as distribuições geográficas dos táxons e as respectivas formações vegetacionais brasileiras onde estes ocorrem foram extraídos, prioritariamente, de revisões taxonômicas e/ou de trabalhos que tratam da distribuição das espécies estudadas. As obras de referências estão mencionadas na tabela 2, numeradas após o nome das espécies, ao final da referida tabela. As denominações dos ambientes de ocorrência das espécies mencionadas pelos autores dos artigos consultados foram mantidas no presente trabalho. As informações foram também obtidas e complementadas, quando necessário, com os dados de etiquetas dos espécimes de herbário. Foram consultados os herbários do estado do Rio de Janeiro, alguns de São Paulo e do Paraná, entretano os do Parque Nacional do Itatiaia (ITA) e do Jardim Botânico do Rio de Janeiro (RB) foram os que forneceram os principais subsídios à identificação taxonômica, sobre as áreas de ocorrência dos táxons e seus respectivos ambientes vegetacionais.

Com base nas informações sobre distribuição geográfica foram evidenciadas as amplitudes geográficas, as faixas de ocorrência, reconhecidos os núcleos predominantes de distribuição e estabelecidos os respectivos padrões adotando-se, com algumas adequações, os padrões definidos para as Leguminosae da Mata Atlântica no estado do Rio de Janeiro (Lima 2000).

A formação florestal do PARNA Itatiaia, no presente trabalho, é tratada como floresta atlântica, segundo o conceito de Oliveira-Filho \& Fontes (2000), e as denominações de florestas montanas e alto-montanas, seguem as delimitações altimétricas da classificação do Veloso et al. (1991).

As denominações de espécies generalistas e especialistas foram atribuídas em relação a preferência de habitat das espécies, considerando-se os diferentes domínos vegetacionais brasilieiros definidos em Joly et al. (1999). Os táxons especialistas foram reconhecidos como de ocorrência exclusiva em formações do Domínio Atlântico e os generalistas os que, além de ocorrerem no Domínio Atlântico, habitam formações outras próprias dos Domínios da Amazônia, do Cerrado e da Caatinga.

O mapa de localização do PARNA Itatiaia foi elaborado a partir de bases cartográficas da ESRI, IBAMA e IBGE e os 
que ilustram a distribuição geográfica das espécies a partir de base cartográfica da ESRI, e das seguintes fontes: Altschul (1964), Anadenanthera colubrina var. colubrina; Barneby \& Grimes (1996), Abarema langsdorfii; Lee \& Lagenheim (1975), Hymenaea courbaril var. altíssima; Lee \& Lagenheim (1975), Hymenaea courbaril var. altíssima;. Lima 2000, Copaifera langsdorfii, Mimosa scabrella; Pennington (1997), Inga marginata, I. vera subsp. affinis, I.striata, I.tenuis, I.sessilis, I.mendoncaei); Vaz \& Tozzi 2003, Bauhinia longifolia.

\section{Caracterização e considerações sobre a área de estudo}

O Parque Nacional do Itatiaia $\left(22^{\circ} 15^{\prime} \mathrm{e}\right.$ $22^{\circ} 30^{\prime} \mathrm{S}$; 4430'e $44^{\circ} 45^{\prime} \mathrm{W}$ ) está localizado na Região Sudeste do Brasil, no sudoeste do estado do Rio de Janeiro, nos municípios de Resende e Itatiaia, e ao sul de Minas Gerais, em Bocaina de Minas e Itamonte, abrangendo uma área de 28.155,97 hectares (http:// www.ibama.gov.br/). Em relação ao relevo, o maciço do Itatiaia faz parte das elevações da cadeia montanhosa e interiorana da Serra da Mantiqueira (Fig. 1).

A geomorfologia da região caracterizase por ser um dos grandes afloramentos rochosos do mundo, constituído por rochas do tipo nefelino e por massas de sienito (SegadasVianna 1965), tipo este raro no Brasil encontrado, além do Itatiaia, em Poços de Caldas (MG) e na Ilha de São Sebastião no litoral de São Paulo (Ribeiro \& Medina 2002). O Plano de Manejo do Parque (MA-IBDF \& FBCN 1982) destaca como pontos relevantes: as Agulhas Negras, com 2.787 metros de altitude, onde se encontra o Pico do Itatiaiassu, que dominam a região do Planalto do Itatiaia, as Prateleiras (2.540 metros), a Serra Negra (2.560 metros), a Pedra do Couto (2.682 metros), o Pico da Maromba (2.607 metros) e a Cabeça do Leão (2.408 metros); a Pedra

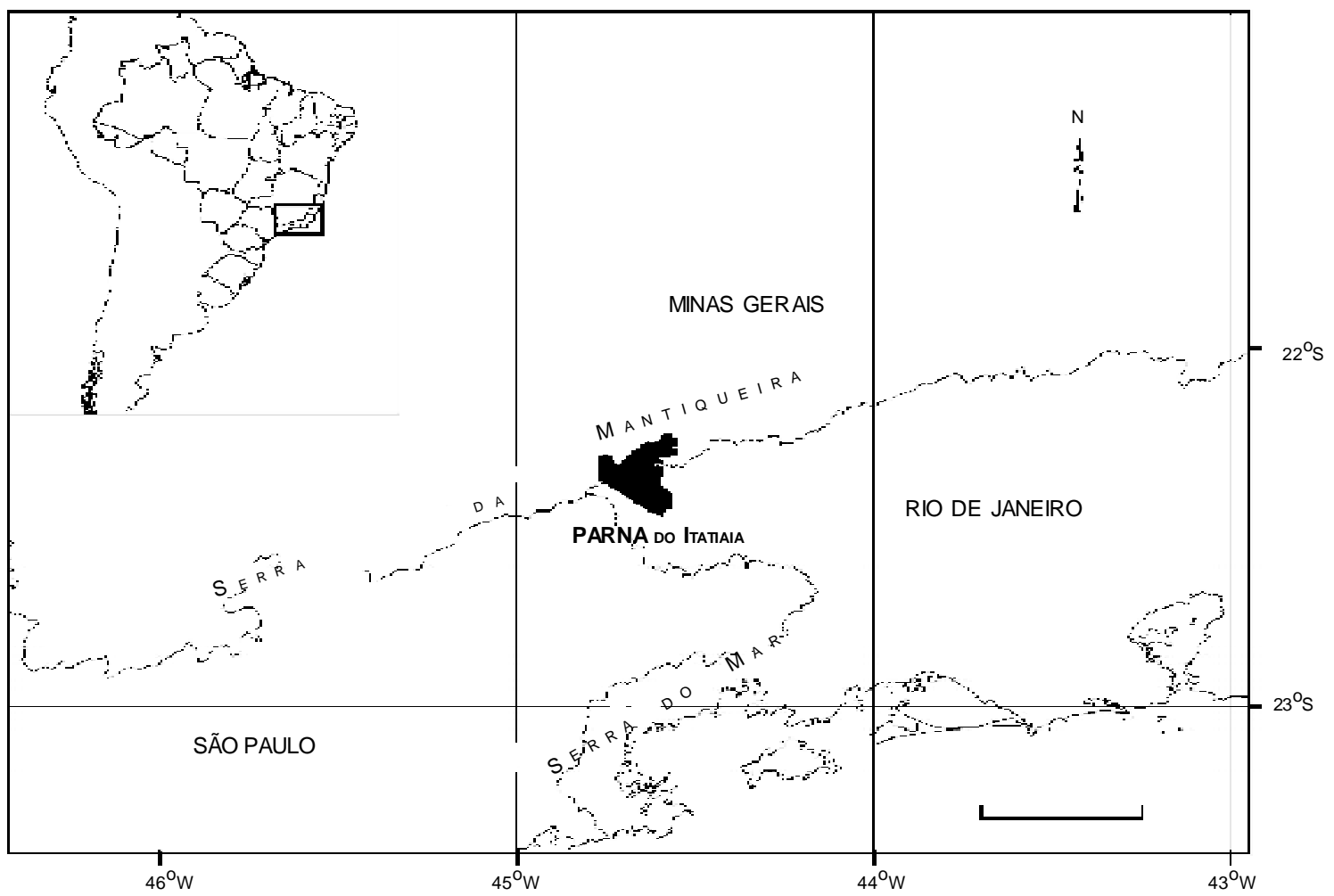

Figura 1 - Localização do PARNA Itatiaia. 
Furada, a oeste acima de 2.500 metros;os Dois Irmãos, a leste em altitude de 2.400 metros; e os Três Picos, com pouco mais de 1.700 metros de altitude. Segundo Safford (1999 a), há dúvidas se os picos do Itatiaia foram realmente submetidos aos processos de glaciação ocorridos durante o Pleistoceno. Clapperton apud Safford 1999a caracteriza o Itatiaia como o único na América do Sul, além dos Andes, que deve muito de sua origem aos processos geocriogênicos do Quaternário.

A hidrografia, segundo Brade (1956) e o MA-IBDF \& FBCN (1982), destaca-se pelas bacias do rio Paraíba do Sul e do rio Paraná e os rios que nascem no Parque seguem seus cursos d'agua em direção a estas bacias, onde desaguam. O rio Campo Belo, que forma as cachoeiras Itaporani, Piturendaba, Poranga e Tupie, e o rio Salto são considerados os componentes mais importantes na rede de drenagem da região. O Ribeirão das Flores, principal afluente do Campo Belo, forma, a $1.100 \mathrm{~m}$ de altitude, a cascatinha do Maromba e o famoso Véu da Noiva. Os rios Baependi, Aiuruoca, Grande pertencem a bacia do rio Paraná e o rio Preto, é importante afluente do Paraíba do Sul.

O clima, segundo a classificação de Koeppen (Bernardes 1952), é do tipo temperado com estação seca (Cwa). Os efeitos climáticos produzidos sobre a vegetação da região foram estudados em diferentes níveis altitudinais do maciço do Itatiaia por SegadasVianna (1965) e Segadas-Vianna \& Dau (1965) que identificaram duas estações para a região: a estação seca e fria, no período de junho a agosto, e a chuvosa e quente, nos meses de dezembro a fevereiro. O clima da região mais baixa, de 400 a 700 metros de altitude, é do tipo Cwa; em altitudes de 700 a 2.000 metros o clima é do tipo $\mathrm{Cfb}$ e na região do planalto, 2.000 a 2.400 metros de altitude, o clima é do tipo Cwb (Segadas-Vianna 1965 e Segadas-Vianna \& Dau 1965). Os autores destacam que a estação muito fria e seca do planalto, assim como a alta incidência de geadas, é desfavorável ao estabelecimento da vegetação florestal. Nos cumes, região acima de 2.400 metros de altitude, além da estação fria e seca ser ainda mais intensa ocorre a constante presença de ventos secos e frios de alta intensidade (Segadas-Vianna \& Dau 1965). Safford (1999b), utilizando técnicas de análise multivariada associadas às informações de Segadas-Vianna \& Dau (l.c.), concluiu que as congruências macroclimáticas evidenciadas refletem bases ambientais de fortes conecções biogeográficas entre os Andes e o sudeste do Brasil (campos de altitude do Planalto do Itatiaia) e, neste contexto, paralelismos evolutivos e ecológicos devem ter ocorrido em ambas as biotas destes sistemas montanhosos neotropicais.

A vegetação do Itatiaia foi descrita pela primeira vez, segundo Segadas-Vianna (1965), por Ule, em 1895, em três principais níveis: a região baixa, até 600 metros de altitude; a região de floresta de 600 a 1.700 metros de altitude; e a região de campos, em altitudes superiores a 2.000 metros, sendo esta subdividida em cinco sub-regiões. Brade (1956) reconheceu: a mata higrófila tropical e subtropical, para a região baixa do Itatiaia; a mata de transição da região mais elevada, na faixa entre 1.200 e 1.800 metros de altitude; a região de Araucária, entre 1.600 e 2.300 metros de altitude, caracterizada pela distribuição descontínua de indivíduos de Araucaria angustifolia (Bertol.) Kuntze; e a vegetação do planalto acima de 2.000 metros de altitude. Segadas-Vianna (1965) definiu a vegetação com base em faixas altimétricas caracterizadas, na maioria das vezes, pelas espécies vegetais e animais, consideradas exclusivas dos andares de vegetação. Os "andares de vegetação" estabelecidos por Segadas-Vianna (1965) abrangeram cinco faixas altimétricas: planície de 400 a 700 metros de altitude; montanhainferior de 700 a 1.100 metros de altitude; montanha média 1.100 a 1.700 metros de altitude; montanha superior de 1.700 a 2.000 metros de altitude; planalto de 2.000 a 2.400 metros de altitude e cumes de 2.400 a 2.770 metros de altitude. 
Ururahy et al. (1983) classificaram a vegetação do Itatiaia como floresta ombrófila densa montana e, acima de 1.500 metros de altitude, como refúgio ecológico. No sistema de classificação do IBGE, Veloso et al. (1991) citaram "...Minas Gerais (Itatiaia)" como um dos exemplos de ocorrência da formação floresta estacional semidecidual montana. Guedes-Bruni (1998) reconheceu a vegetação como floresta ombrófila densa montana.

No presente trabalho a formação florestal do PARNA Itatiaia é tratada no conceito da floresta atlântica (Oliveira-Filho \& Fontes 2000), sendo a floresta ombrófila densa, segundo sistema de classificação do IBGE (Veloso et al. 1991) e o mapeamento de áreas do sudeste (Oliveira-Filho \& Fontes 2000), predominante na área de estudo.

O grau de conservação da vegetação do Parque Nacional do Itatiaia é bastante variado. Algumas porções da formação florestal ainda se apresentam como matas em bom estado de conservação. Entretanto, constata-se grandes trechos de vegetação pertubada, principalmente, na faixa de altitude entre 600 e 1.000 metros. A influência do homem na vegetação do Itatiaia, mencionada por Brade (1956), reflete as ações antrópicas, principalmente, direcionadas à lavoura e pastagens, praticadas em toda a região da Mantiqueira (Mendes Jr. et al. 1991); atualmente, o turismo e a urbanização desordenados somam-se a estas ações. Os incêndios sempre fizeram parte dos processos devastadores freqüentes na região, entretanto, atualmente, podem ser considerados como a ameaça mais constante à vegetação e à flora do PARNA Itatiaia, inclusive nas regiões mais elevadas.

\section{Resultados e Discussão}

A riqueza e a diversidade taxonômica da família Leguminosae no PARNA Itatiaia, no tocante aos táxons arbustivos e arbóreos, estão expressas no total de 50 táxons específicos, e/ou infra-específicos, subordinados a 30 gêneros, assim distribuídos: oito gêneros e 15 spp. em Caesalpinoideae, sete gêneros e 14 spp. em Mimosoideae e 15 gêneros e 23 spp. em Papilionoideae (Morim 2002). Os padrões de distribuição foram reconhecidos para 48 espécies, considerando-se que as demais permanecem identificadas apenas na categoria taxonômica de gênero.

Na flora local a distribuição do grupo é predominante na formação montana do PARNA Itatiaia em uma faixa altitudinal de 700 até cerca de 1.200 metros e a partir desta cota altitudinal a riqueza de espécies de Leguminosae decresce. Esta redução na riqueza de espécies foi constatada por Brade (1956) e Segadas-Vianna (1965) para espécies de outras famílias da flora arbórea do Itatiaia. Segundo Gentry (1995) o declínio na riqueza de espécies, em consequiência do aumento de altitude, é um certo padrão em florestas tropicais.

A distribuição geográfica das espécies de Leguminosae do PARNA Itatiaia abrange três macrorregiões (Tab. 1): América do Sul, América Central e México (12\% dos táxons); América do Sul (23\% dos táxons) e restritos ao Brasil (65\% dos táxons).

A partir desta avaliação foram definidos seis padrões de distribuição que têm como referência a faixa predominante de ocorrência, na qual os táxons exibem distribuições

Tabela 1 - Porcentagem e número de espécies de Leguminosae do PARNA Itatiaia por distribuição em macrorregiões

\begin{tabular}{lcl}
\hline Macrorregiões & $\mathbf{n}^{\mathbf{0}}$ espécies & $\%$ \\
\hline I. América do Sul, A. Central e México & 6 & $12 \%$ \\
II. América do Sul & 11 & $23 \%$ \\
III. Distribuição restrita ao Brasil & 31 & $65 \%$ \\
Total & 48 & $100 \%$ \\
\hline
\end{tabular}


Tabela 2 - Padrões de distribuição, relação das espécies e elementos florísticos, quanto as preferências de habitat, das Leguminosae do PARNA Itatiaia.

\begin{tabular}{|c|c|c|}
\hline Padrões de distribuição & Espécies & $\begin{array}{r}\text { Elementos } \\
\text { florísticos } \\
\end{array}$ \\
\hline 1. Neotropical & $\begin{array}{l}\text { 1. Inga marginata Willd. } \\
\text { 2. Inga vera subsp. affinis (DC.) T.D. Penn. }{ }^{1} \\
\text { 3. Lonchocarpus cultratus (Vell.)Az.-Tozzi \& H.C.Lima } \\
\text { 4. Machaerium hirtum (Vell.) Stellfeld }{ }^{2,3} \\
\text { 5. Peltophorum dubium (Spreng.) Taub.,5 } \\
\text { 6. Platypodium elegans } \text { Vogel }^{4,5} \\
\text { 7. Pterocarpus rohrii } \text { Vahl }^{6} \\
\text { 8. Schyzolobium parahyba (Vell.) Blake }{ }^{4,5} \\
\text { 9. Senna pendula (Willd.) Irwin \& Barneby }\end{array}$ & $\begin{array}{l}\text { Generalista } \\
\text { Generalista } \\
\text { Generalista } \\
\text { Generalista } \\
\text { Generalista } \\
\text { Generalista } \\
\text { Generalista } \\
\text { Generalista } \\
\text { Generalista }\end{array}$ \\
\hline $\begin{array}{l}\text { 2. América do Sul } \\
\text { ocidental-centro-oriental }\end{array}$ & $\begin{array}{l}\text { 10. Bauhinia longifolia } \text { (Bong.) Steud. }{ }^{8} \\
\text { 11. Collaea speciosa } \text { DC. }{ }^{9,10} \\
\text { 12. Dalbergia frutescens (Vell.) Britton var. frutescens }{ }^{11} \\
\text { 13. Erytrhina falcata } \text { Benth. }{ }^{12} \\
\text { 14. Inga striata } \text { Benth. }{ }^{1}\end{array}$ & $\begin{array}{l}\text { Generalista } \\
\text { Generalista } \\
\text { Generalista } \\
\text { Generalista } \\
\text { Generalista }\end{array}$ \\
\hline 3. Brasil centro-oriental & 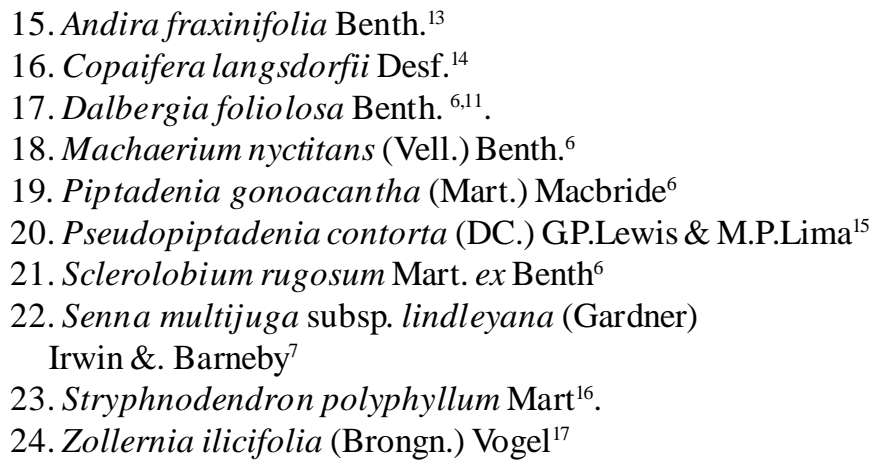 & $\begin{array}{l}\text { Generalista } \\
\text { Generalista } \\
\text { Generalista } \\
\text { Generalista } \\
\text { Especialista } \\
\text { Generalista } \\
\text { Generalista } \\
\text { Generalista } \\
\text { Generalista } \\
\text { Generalista }\end{array}$ \\
\hline $\begin{array}{l}\text { 4. Brasil atlântico } \\
\text { nordeste-sudeste-sul }\end{array}$ & $\begin{array}{l}\text { 25. Abarema langsdorfii (Benth.) Barneby et } \mathrm{Grimes}^{18} \\
\text { 26 Anadenanthera colubrina } \text { (Vell.) Brenan var. colubrina }{ }^{19} \\
\text { 27. Bauhinia forficata Link subsp. forficata }{ }^{20} \\
\text { 28. Chamaecrista ensiformis (Vell.) Irwin \& Barneby } \\
\text { 29. Dalbergia nigra } \text { (Vell.) Allemão ex Benth }{ }^{11} \text {. } \\
\text { 30. Inga tenuis (Vell.) Mart. } \\
\text { 31. Myrocarpus frondosus Allemão } \\
\text { 32. Senna affinis } \text { (Benth.) Irwin \& Barneby } \\
\text { 33. Zollernia glabra (Spreng.) Yakovlev }{ }^{17}\end{array}$ & $\begin{array}{l}\text { Especialista } \\
\text { Especialista } \\
\text { Especialista } \\
\text { Especialista } \\
\text { Especialista } \\
\text { Especialista } \\
\text { Generalista } \\
\text { Especialista } \\
\text { Especialista }\end{array}$ \\
\hline $\begin{array}{l}\text { 5. Brasil atlântico } \\
\text { sudeste-sul }\end{array}$ & $\begin{array}{l}\text { 34. Dahlstedtia pinnata }\left(\text { Benth.) } \text { Malme }^{5}\right. \\
\text { 35. Inga barbata Benth. }{ }^{1} \\
\text { 36. Inga sessilis (Vell.) Mart. }{ }^{1} \\
\text { 37. Mimosa scabrella } \text { Benth }^{22,23} \text {. } \\
\text { 38. Senna organensis } \text { (Harms) Irwin \& Barneby }{ }^{7}\end{array}$ & $\begin{array}{l}\text { Especialista } \\
\text { Generalista } \\
\text { Especialista } \\
\text { Especialista } \\
\text { Especialista }\end{array}$ \\
\hline 6. Brasil atlântico sudeste & $\begin{array}{l}\text { 39. Hymenaea courbaril var. altissima (Ducke)Lee \& } \text { Lang }^{24} \\
\text { 40. Inga mendoncaei } \mathrm{Harms} \mathrm{s}^{1} \\
\text { 41. Ormosia friburgensis Taub. ex } \mathrm{Harms}^{6} \\
\text { 42. Pseudopiptadenia leptostachya }\left(\text { Benth.) Rauschert }{ }^{15}\right. \\
\text { 43. Sclerolobium friburgense Harms }{ }^{6} \\
\text { 44. Senna itatiaiae Irwin \& Barneby }\end{array}$ & $\begin{array}{l}\text { Especialista } \\
\text { Especialista } \\
\text { Especialista } \\
\text { Especialista } \\
\text { Especialista } \\
\text { Especialista }\end{array}$ \\
\hline
\end{tabular}




\begin{tabular}{llc}
\hline Padrões de distribuição & Espécies & $\begin{array}{c}\text { Elementos } \\
\text { florísticos }\end{array}$ \\
\hline & 45. Senna macranthera (Collad.)Irwin \& Barneby & Especialista \\
& var. macranthera & \\
& 46. Swartzia oblata R.S. Cowan 25,26 & Especialista \\
& 47. Swartzia pilulifera Benth. ${ }^{25,26}$ & Generalista \\
& 48. Swartzia submarginata (Benth.) Mansano ${ }^{25,26}$ & Especialista \\
\hline
\end{tabular}

Referências de distribuições geográficas e ocorrências em formações vegetacionais: ${ }^{1}$ Pennington (1997); ${ }^{2}$ Ducke (1949), ${ }^{3}$ Sartori \& Tozzi (1998), ${ }^{4}$ Prado \& Gibbs (1993); ${ }^{5}$ Lima (2000); ${ }^{6}$ Lima et al. (1994); ${ }^{7}$ Irwin \& Barneby (1982); ${ }^{8}$ Vaz \& Tozzi (2003); ${ }^{9}$ Garcia (1989); ${ }^{10}$ Fortunato (1995); ${ }^{11}$ Carvalho (1997); ${ }^{12}$ Krukoff \& Barneby (1974); ${ }^{13}$ Pennington (2003); ${ }^{14}$ Oliveira-Filho \& Ratter (1995) ${ }^{15}$ Lewis \& Lima 1989-90; ${ }^{16}$ Occhioni Martins (1974); ${ }^{17}$ Mans ano, Tozzi \& Lewis (2004): ${ }^{18}$ Barneby \& Grimes (1996); ${ }^{19}$ Altschul (1964); ${ }^{20}$ Vaz \& Silva (1995); ${ }^{21}$ Sartori \& Tozzi (2004); ${ }^{22}$ Burkart (1979); ${ }^{23}$ Barneby (1991); ${ }^{24}$ Lee \& Langenheim (1975); ${ }^{25}$ Mansano \& Tozzi (1999); ${ }^{26}$ Mansano \& Tozzi (2001).

contínuas ou não. Os alcances geográficos dos táxons são de maior ou menor amplitudes e refletem núcleos de distribuição mais restritos, assim como exigências ecológicas associadas às formações vegetacionais onde se difundem.

Os padrões estabelecidos, os táxons estudados e a indicação das espécies como elementos florísticos estão reunidos na tabela 2 e são discutidos a seguir.

1. Distribuição neotropical (Tab. 2, Figs. 2-3): abrange espécies com distribuições muito amplas, contínuas ou disjuntas, com áreas de ocorrências predominantemente localizadas na faixa neotropical. O México e a América Central são os limites norte de distribuição e o limite sul, o norte da Argentina. As espécies que exibem este padrão são: Inga marginata (Fig. 2), Inga vera subsp. affinis (Fig. 3), Lonchocarpus cultratus, Machaerium hirtum, Peltophorum dubium, Platypodium elegans, Pterocarpus rohrii, Schyzolobium parahyba e Senna pendula. No PARNA Itatiaia a ocorrência destes táxons foi verificada em uma faixa entre 650 e 1.100 metros de altitude, em localidades conhecidas como Benfica, Mont Serrat, nas proximidades das margens do rio Campo Belo e no Maromba. Deste conjunto de espécies destaca-se Inga vera subsp. affinis que alcança as maiores altitudes, até 1.800 metros, na orla da mata, no caminho para o planalto, e no interior da mata montana, em transição para alto-montana, e Pterocarpus rohrii como freqüentes em altitude de 900 metros. Alguns indivíduos de Schyzolobium parahyba são encontrados apenas nos arredores do Museu Botânico, em locais de vegetação alterada, sugerindo ser esta uma espécie cultivada no PARNA Itatiaia.

Peltophorum dubium e Platypodium elegans incluem-se no grupo de espécies citadas por Prado \& Gibbs (1993) que ilustram os padrões de distribuições de táxons em florestas estacionais da América do Sul. Platypodium elegans é um dos exemplos de táxons, mencionados pelos autores, que apresenta uma distribuição bastante complexa (Prado \& Gibbs 1993).

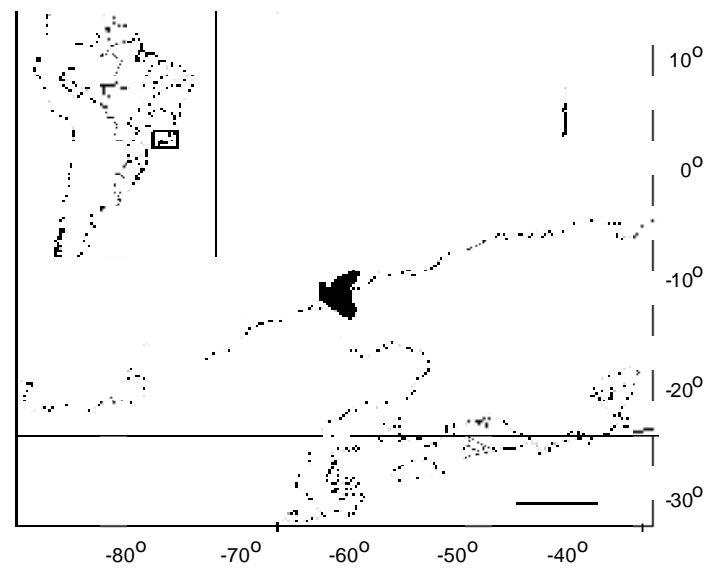

Figura 2 - Inga marginata 


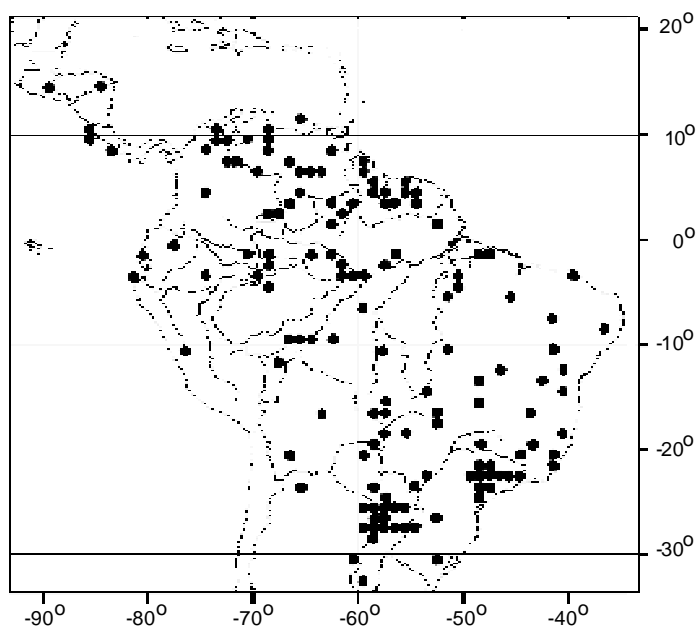

Figura 3 - Inga vera subsp. affins

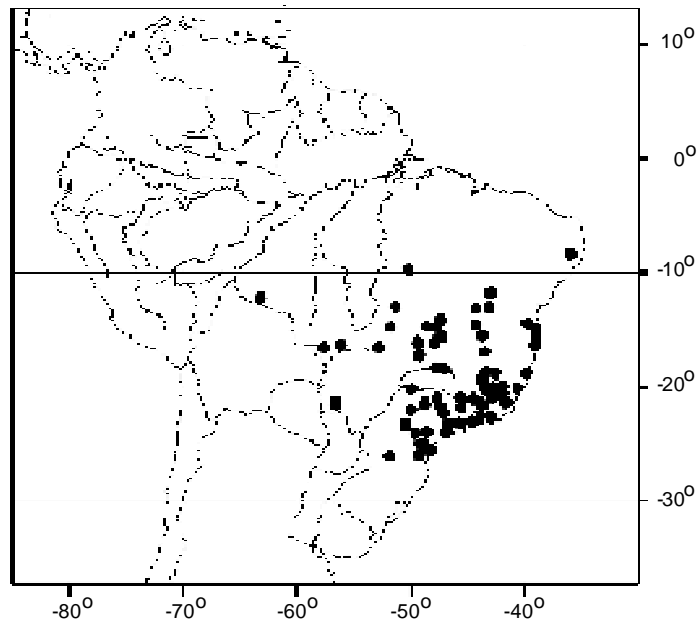

Figura 4 - Bauhinia longifolia

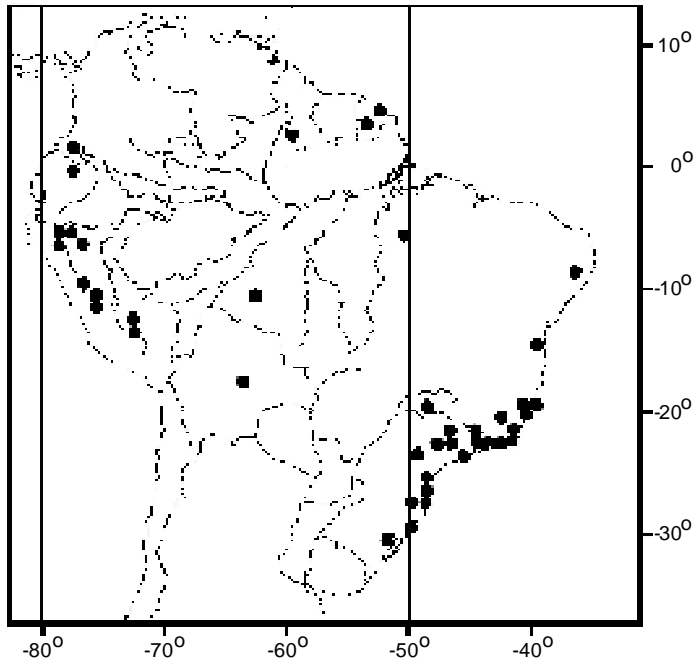

Figura 5 - Inga striata
As espécies incluídas neste padrão habitam formações de diferentes domínios vegetacionais e são elementos florísticos generalistas na flora do PARNA Itatiaia.

2. Distribuição América do Sul ocidentalcentro-oriental (Tab. 2, Figs. 4-5): a faixa de ocorrência predominante neste padrão abrange as áreas oeste, centro e leste da América do Sul. Os extremos mais ao norte, Venezuela, Suriname ou ainda a Guiana, são alcançados por alguns dos táxons; o limite meridional é, em geral, o sul do Brasil. O referido padrão é reconhecido nos seguintes táxons: Bauhinia longifolia (Fig. 4), Collaea speciosa, Dalbergia frutescens var. frutescens, Erythrina falcata e Inga striata (Fig. 5). No PARNA Itatiaia as espécies ocorrem, principalmente, em altitudes entre 650 e 900 metros, em áreas abertas ou no interior da formação montana, em geral, a 900 metros de altitude. Alguns indivíduos de D. frutescens var. frutescens são encontrados em trechos de mata a 1.500-1.700 metros de altitude; $C$. speciosa e E. falcata alcançam altitudes superiores a 1.700 metros, sendo que C.speciosa ocorre em áreas de transição entre a formação montana e alto-montana, em altitude de 2.000 metros.

Bauhinia longifolia, com distribuição relativamente contínua, ocorre no Peru, Bolívia e Paraguaie, na faixa centro-oriental do Brasil, em áreas do centro-oeste, nordeste, sudeste e, no sul, até o Paraná (Vaz \& Tozzi 2003). É frequente nas formações florestais dos domínios do cerrado, campo rupestre e da floreta atlântica (Vaz \& Tozzi 2003).

As ocorrências mais ao norte do continente são registradas para Dalbergia frutescens var. frutescens, na Venezuela $\mathrm{e}$ Guiana (Carvalho 1997), e em Inga striata, na Guiana e Suriname (Pennington 1997). Dalbergia frutescens var. frutescens, no Brasil, ocorre em floresta de galeria, restinga, na formação florestal atlântica, e em floresta de araucária, tendo como limite sul o norte da Argentina (Carvalho 1997); Inga striata, além 
de muito comum em ampla faixa da formação florestal atlântica, desde o nordeste, Pernambuco, até o Rio Grande do Sul, é registrada ainda para as florestas montanas dos Andes, no Peru e Equador (Pennington 1997).

As espécies Collaea speciosa e Erythrina falcata, comparadas as demais incluídas neste padrão, são as que possuem uma faixa de ocorrência mais restrita. Collaea speciosa tem distribuição registrada para o Peru, Bolivia, Paraguai e Argentina (Garcia 1989, Fortunato 1995) e no Brasil, segundo dados do herbário, na Bahia, Minas Gerais, Rio de Janeiro e São Paulo. No Rio de Janeiro ocorre em floresta ombrófila densa montana e para os demais estados só foram encontradas como citações de ambientes, locais abertos e capoeiras. O táxon é considerado um complexo variável eos espécimes que ocorrem no Brasil são distintos das formas típicas do Peru e da Bolivia (Fortunato 1995). Erythrina falcata, segundo Krukoff \& Barneby (1974), ocorre em regiões sub-andinas do Peru e da Bolívia, no Paraguai e no norte da Argentina. No Brasil difunde-se nas Regiões Sudeste e Sul, no domínio florestal atlântico, tendo apenas o espécime tipo, no Maranhão (Krukoff \& Barneby 1974). Erythrina falcata e, provavelmente, Collaea speciosa poderiam ser correlacionadas ao elemento florístico andino reconhecido por Brade (1956) para a Serra do Itatiaia.

As espécies reconhecidas neste padrão são consideradas generalistas.

3. Brasil centro-oriental (Tab. 2; Figs. 6-7): a principal faixa de distibuição dos táxons, neste padrão, compreende áreas do centrooeste, do nordeste, sudeste e sul do Brasil, tendo, em geral, como limites, ao norte, os estado do Ceará ou da Bahia e, ao sul, o Paraná ou Santa Catarina. Incluem-se neste padrão: Andira fraxinifolia, Copaifera lang sdorfii (Fig. 6), Dalbergia foliolosa, Machaerium nyctitans, Piptadenia gonoacantha, Pseudopiptadenia contorta (Fig. 7), Sclerolobium rugosum, Senna multijuga subsp. lindleyana, Stryphnodendron polyphyllum e Zollernia ilicifolia. No PARNA Itatiaia estas espécies são encontradas, principalmente, na formação montana na faixa entre 600 e 900 metros de altitude, no interior da mata, nas proximidades do rio Campo Belo, e também são comuns em locais de vegetação alterada. Dalbergia foliolosa e Sclerolobium rugosum foram registradas em trechos de mata, na formação montana em transição para alto-montana, em faixa altitudinal entre 1.400 e 1.900 metros, na localidade de Macieiras.

Andira fraxinifolia ocorre no Distrito Federal e Goiás e, também, do Ceará a Santa

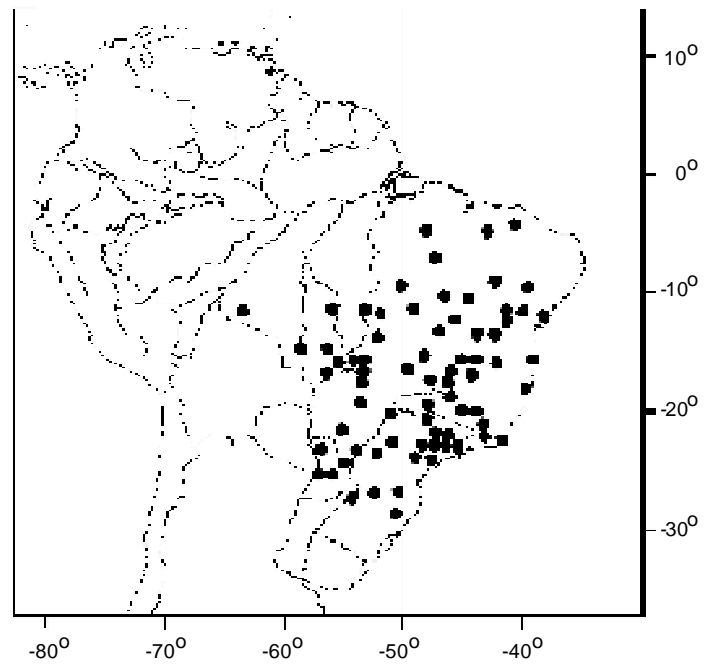

Figura 6 - Copaifera langsdorfii

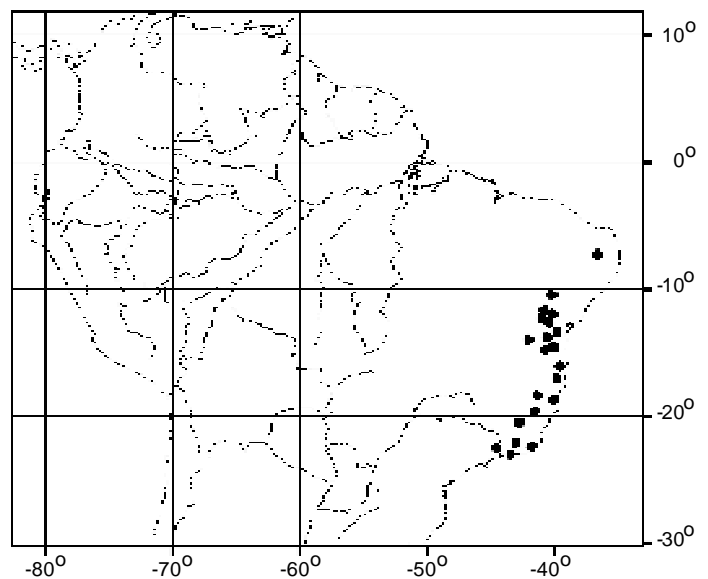

Figura 7 - Pseudopiptadenia contorta 
Catarina em formações da floresta pluvial atlântica, restinga, campo rupestre e ainda em vegetação secundária (Pennington 2003).

Copaifera langsdorfii, segundo dados de herbário e Oliveira-Filho \& Ratter (1995), é muito comum no centro-oeste, nordeste e sudeste do Brasil, principalmente, em áreas de cerrado, floresta de galeria, caatinga e floresta estacional. Oliveira-Filho \& Ratter (1995) registram C. langsdorfii como uma das treze espécies de mais alta freqüência nas florestas de galeria e com uma distribuição expressiva nas florestas semidecíduas paranaenses, difundindo-se também no cerrado e, ainda, em poucas áreas das províncias amazônica e atlântica.

Zollernia ilicifolia ocorre no centrooeste, apenas no Distrito Federal, e desde a Paraíba até o Paraná em formações da floresta pluvial atlântica, da floresta estacional, cerrado e caatinga (Mansano et al. 2004).

Pseudopiptadenia contorta ocorre no nordeste, Paraíba e Bahia, e no sudeste, em todos os estados, em ambientes do Domínio da Caatinga arbórea, em matas de restinga e nas formações do Domínio Florestal Atlântico (Lewis \& Lima 1989-90).

Stryphnodendron polyphyllum é frequente nos cerrados e campos rupestres do nordeste, principalmente na Bahia(Lewis 1987), e no sudeste (Occhioni Martins 1974, 1981), com exceção do Espírito Santo, em floresta estacional semidecidual e em floresta ombrófila densa. Segundo Occhioni Martins (1981) esta é a única espécie do gênero que ocorre no Rio de Janeiro, principalmente, em trechos da Serra da Mantiqueira e da Serra do Mar.

Machaerium nyctitans e Sclerolobium rugosum são registradas para o nordeste, Bahia, na Região Sudeste, em todos os estados, e no sul, apenas M.nyctitans chega ao Paraná e Santa Catarina, ocorrendo na floresta ombrófila densa e na floresta estacional do planalto meridional (Lima \& al.1994).

Dalbergia foliolosa é frequente em matas ciliares em áreas do cerrado do Brasil mas, também, é muito comum e característica da floresta pluvial atlântica montana da Serra da Mantiqueira e da Serra do Mar, nos estados de Minas Gerais, Rio de Janeiro e São Paulo (Lima et al.1994, Carvalho 1997).

Em relação à flora do PARNA Itatiaia observa-se, neste padrão, o predomínio de espécies generalistas.

4. Brasil atlântico nordeste-sudeste-sul (Tab. 2, Figs. 8-10): a principal faixa de distribuição neste padrão é a área que abrange desde o nordeste, principalmente, a Bahia, até o sul do Brasil, em geral, o Paraná. Entre as espécies estudadas cita-se: Abarema langsdorfii (Fig. 8), Anadenanthera colubrina var. colubrina (Fig. 9), Bauhinia forficata subsp. forficata, Chamaecrista ensiformis, Dalbergia nigra, Inga tenuis (Fig. 10), Myrocarpus frondosus, Senna affinis e Zollernia glabra. A ocorrência destas espécies no PARNA Itatiaia foi verificada em uma faixa altitudinal entre $600 \mathrm{e}$ 1.000 metros, em localidades conhecidas como Benfica, Lago Azul, e nas proximidades do rio Campo Belo, em trechos da formação montana mais preservada.

As distribuições de Bauhinia forficata subsp. forficata, Abarema langsdorfii $e$ Myrocarpus frondosus são similares e refletem as maiores amplitudes geográficas dos táxons incluídos neste padrão. A faixa de distribuição da Bahia até o Rio Grande do Sul, interiorizando em Minas Gerais, é predominate e comum às três espécies: $B$. forficata subsp. forficata, segundo Vaz \& Silva (1995) e dados de herbário, tem como limites norte Alagoas e como sul, o estado de Santa Catarina, ocorrendo nas formações de floresta atlântica (senso Oliveira-Filho \& Fontes 2000); A. langsdorfii difunde-se da Bahia até Santa Catarina, em restinga (Barneby \& Grimes 1996), e, pelas informações dos autores e dados de herbário, em formações montanhosas da floresta ombrófila densa, tornando-se mais rara nas florestas estacionais da Serra da Mantiqueira e leste de Minas Gerais (Barneby \& Grimes 1996). Myrocarpus frondosus, 


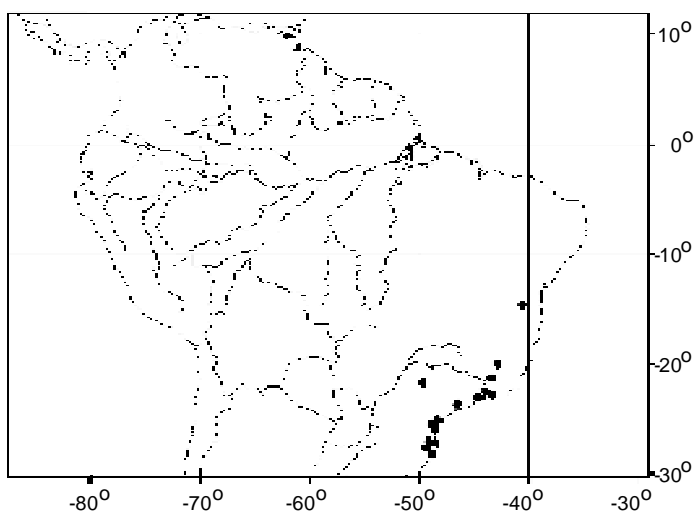

Figura 8 - Abarema lagsdorfii

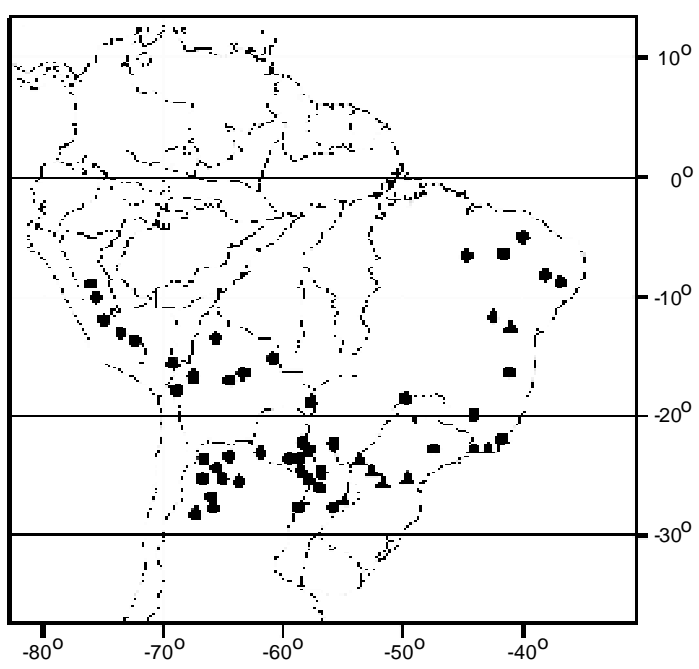

Figura 9 - Anadenanthera colubrina: Anadenanthera colubrina var. colubrina (p ); A. colubrina var. cebil (I )

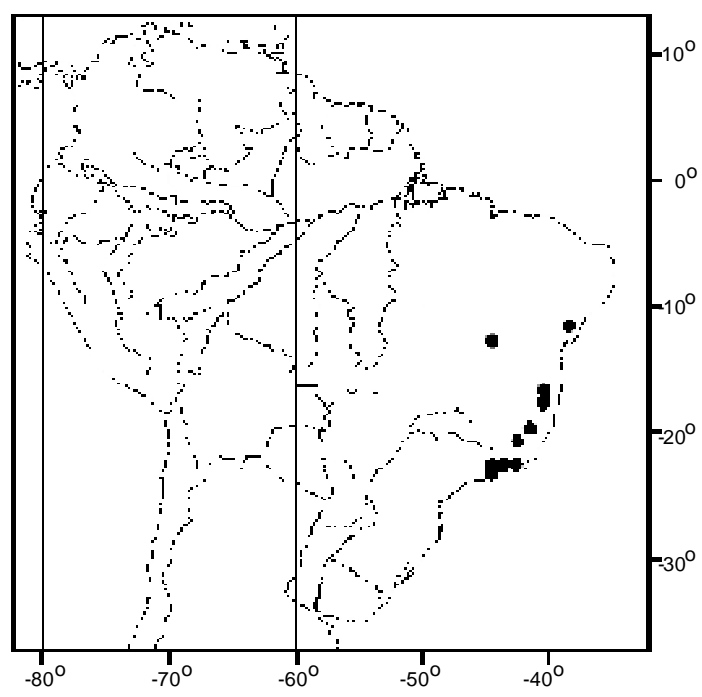

Figura 10 - Inga tenuis embora com um núcleo expressivo de distribuição na faixa da Bahia ao Rio Grande do Sul, em formações florestais de florestas estacionais, decidual e semidicual, da floresta ombrófila densa e da floresta ombrófila mista, ocorre também no sudoeste do Paraguai e no norte da Argentina (Sartori \& Tozzi 2004).

Anadenanthera colubrina var. colubrina, segundo Altschul (1964), distribuise no nordeste, na Bahia, no sudeste, no Rio de Janeiro e São Paulo, no sul do Brasil, no Paraná, e na Argentina, em Misiones. Prado \& Gibbs (1993) assinalaram que a variedade típica distribui-se simpatricamente com $A$. colubrina var. cebil (Griseb.) Altschul nas áreas de caatinga da Bahia e também em Misiones e de forma alopátrica no estado do Rio de Janeiro e nas florestas do planalto de São Paulo e Paraná. Os autores consideraram A. colubrina var. cebil um táxon paradigma para o padrão, por eles denominado," Arco das formações estacionais residuais do Pleistoceno". As terras altas da Região Sudeste do Brasil foram apontadas como prováveis locais de origem de A. colubrina e ainda como o centro de origem do gênero (Altschul 1964).

Dalbergia nigra e Inga tenuis possuem núcleos de distribuição muito similares: I. tenuis tem como limite norte o estado de Sergipe e sul o Rio de Janeiro. Nesta faixa, ocorre na floresta pluvial e em áreas de transição com a restinga (Pennington 1997); D. nigra ocorre do sul da Bahia até São Paulo, na floresta ombrófila densa, e também em em Minas Gerais, na floresta estacional semidecidual (Carvalho 1997).

Chamaecrista ensiformis, segundo dados de herbário, ocorre na Bahia, Espírito Santo e Rio de Janeiro, na floresta ombrófila densa e também em restinga; Senna affinis (Irwin \& Barneby 1982) apresenta distribuição semelhante não sendo citada para o Espírito Santo mas, com ocorrência registrada em Minas Gerais.

Zollernia glara apresenta uma área de distribuição muito similar a de Chamaecrista ensiformis, ocorrendo também em São Paulo. 
Em relação a seu habitat a espécie é restrita a floresta pluvial atlântica (Mansano et al. 2004).

Independente das diferentes amplitudes geográficas predominam neste padrão as espécies de Leguminosae especialistas do Domínio Florestal Atlântico.

5. Brasil atlântico sudeste-sul (Tab. 2, Figs. 11-12): este padrão é caracterizado pela faixa de distribuição nas Regiões Sudeste e Sul do Brasil, predominando como limite sul o estado do Paraná. Os seguintes táxons, são reconhecidos: Dahlstedtia pinnata, Inga barbata, I. sessilis (Fig. 11), Mimosa scabrella (Fig. 12) e Senna organensis. Na flora do PARNA Itatiaia a maior parte destas espécies ocorre na faixa de 650 a 1.000 metros de altitude em localid ades citadas como Mont Serrat, Lago Azul e Maromba. Inga sessilis, muito freqüente no Maromba, ocorre também em Macieiras e no caminho para o planalto em uma altitude de até 1.900 metros; Dahlstedtia pinnata foi coletad a também em altitude de 1.300 metros (Três Picos); Mimosa scabrella ocorre em uma faixa entre $1.000 \mathrm{e}$ 1.900 metros, em geral, em trechos de matas pertubadas, em trechos próximos ao planalto, Vargem Grande e Serra Negra.

Os táxons com maiores amplitudes geográficas são: Inga sessis, que se distribui de Minas Gerais ao Rio Grande do Sul (Pennington 1997), em floresta de galeria no cerrado de Minas Gerais, floresta de Araucaria, no Paraná, e em vegetação secundária derivada da floresta pluvial montana (Pennington 1997); Mimosa scabrella possui a mesma distribuição geográfica da espécie anterior, sendo muito comum em locais de vegetação alterada das formações montanas da floresta ombrófila densa e, também, na floresta de araucária (Burkart 1979, Barneby 1991). Ambas apresentam uma distribuição bastante similar a de Araucaria angustifolia (Burkart 1979), táxon de distribuição provavelmente relictual (Ab'Saber1977, Bigarella et al. 1975).
Este grupo de táxons é característico em formações dos complexos montanhosos, da Serra da Mantiqueira e da Serra do Mar. São espécies, predominantemente, especialistas do Domínio Atlântico, no qual o habitat preferido é a floresta atlântica (senso Oliveira-Filho \& Fontes 2000). As espécies deste padrão se relacionadas aos elementos florísticos de Brade (1956) poderiam ser reconhecidas no sub-

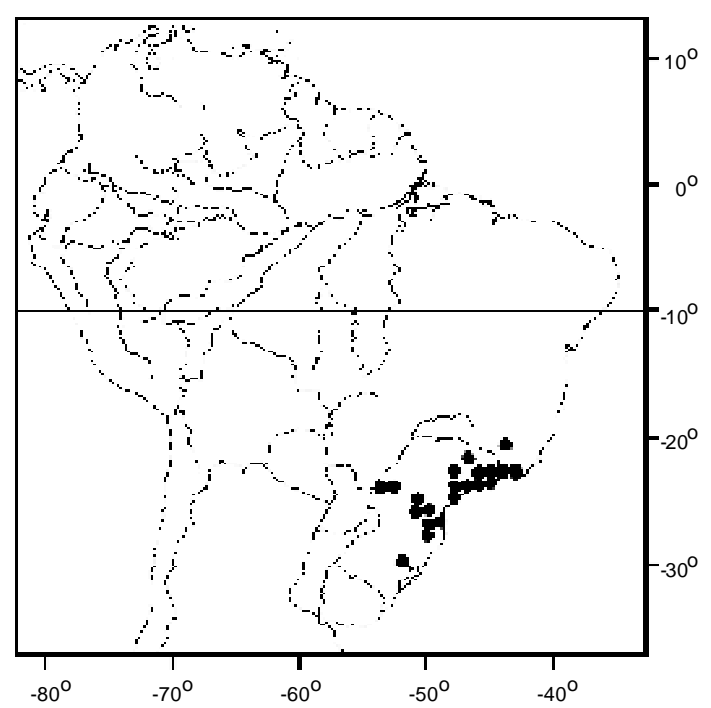

Figura 11 - Inga sessilis

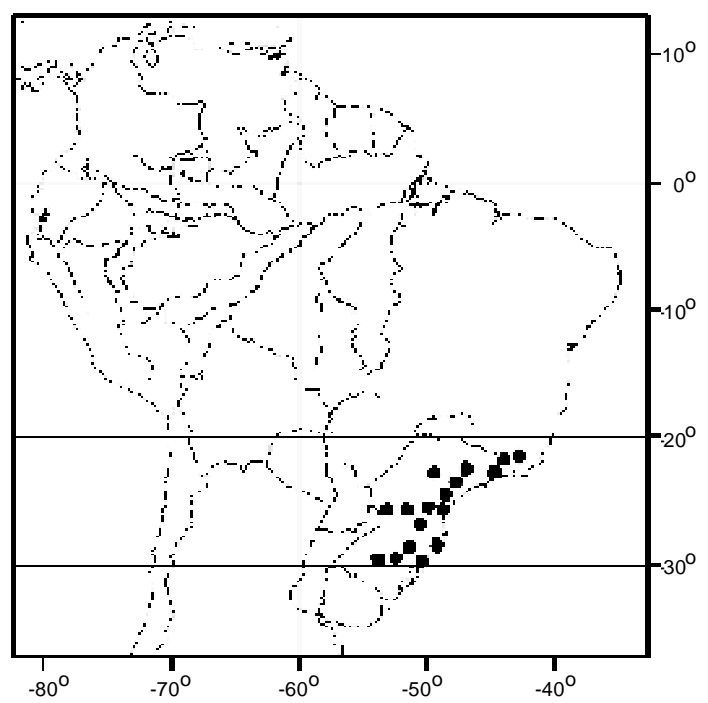

Figura 12 - Mimosa scabrella 
grupo dos elementos florísticos subtropicais das matas higrófilas (senso Brade 1956).

6. Brasil atlântico sudeste (Tab. 2, Figs. 13, 14): a faixa de abrangência deste padrão é restrita à Região Sudeste, principalmente, em locais de maiores altitudes das cadeias da Serra do Mar e da Serra da Mantiqueira. Para a flora do PARNA Itatiaia são reconhecidas, neste padrão, as seguintes espécies: Hymenaea courbaril var. altissima (Fig. 13), Inga mendoncaei (Fig. 14), Ormosia friburgensis, Pseudopiptadenia leptostachya, Sclerolobium friburgensis, Senna itatiaiae, S. macranthera var. macranthera, Swartzia oblata, S. pilulifera e $S$. submarginata. Na flora em estudo este grupo de táxons ocorre em uma faixa de altitude entre 700 e 2.200 metros e, em geral, são as espécies que alcançam as altitudes mais elevadas, como, por exemplo, Senna itatiaiae de ocorrência registrada apenas na formação alto-montana.

Na Região Sudeste, núcleo de distribuição para os táxons incluídos neste padrão, são reconhecidas áreas distintas de ocorrência: Senna macranthera var. macranthera ocorre em cadeias serranas de Minas Gerais, na floresta atlântica do Espírito Santo e Rio de Janeiro, principalmente na Serra dos Órgãos e na Serra da Mantiqueira, e áreas de capoeira (Irwin \& Barneby 1982); Pseudopiptadenia leptostachya ocorre em Minas Gerais, Rio de Janeiro e São Paulo, na floresta ombrófila densa montana das Serra do Mar e da Mantiqueira (Lewis \& Lima 1989-90); Swartzia oblata e S. submarginata são registradas para Minas Gerais, Rio de Janeiro e São Paulo, na floresta pluvial tropical atlântica e na floresta estacional, acrescentandose ainda a ocorrência de $S$. oblata no Espírito Santo (Mansano \& Tozzi 1999; Mansano \& Tozzi 2001); Hymenaea courbaril var. altissima (Lee \& Langenheim 1975); Ormosia friburgensis, e Sclerolobium friburgensis, (Lima et al. 1994), ocorrem no Rio de Janeiro e São Paulo, nas Serra do Mar e na Serra da Mantiqueira, na floresta ombrófila densa montana; Swartzia pilulifera é registrada para Minas Gerais e Rio de Janeiro na floresta pluvial tropical atlântica, floresta estacional e cerrado (Mansano \&Tozzi 1999); Inga mendoncaei e Senna itatiaiae, segundo Pennington (1997) e Irwin \& Barneby (1982), respectivamente, são conhecidas apenas da floresta pluvial montana do estado do Rio de Janeiro, destacando-se que $S$. itatiaiae é conhecida, até o momento, apenas para a flora do PARNA Itatiaia.

As espécies reconhecidas neste padrão são elementos florísticos especialistas do

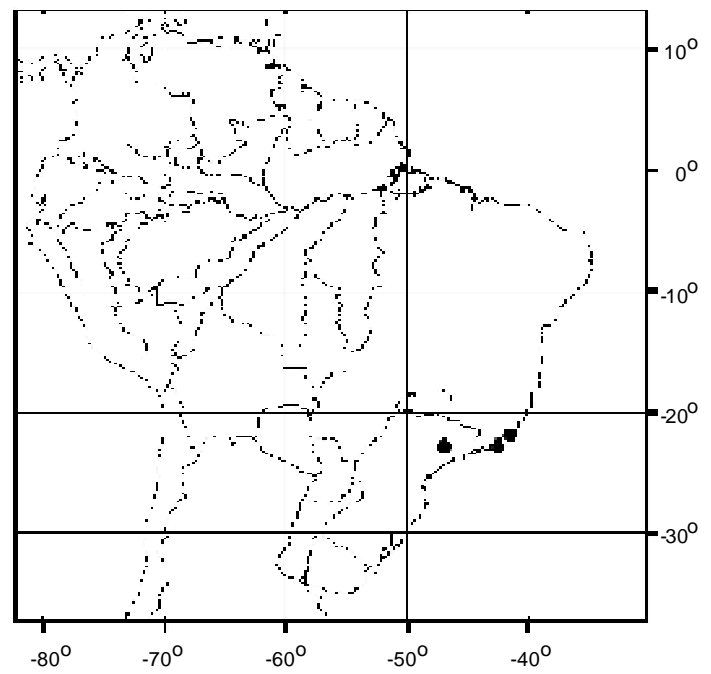

Figura 13 - Hymenaea courbaril var. altissima

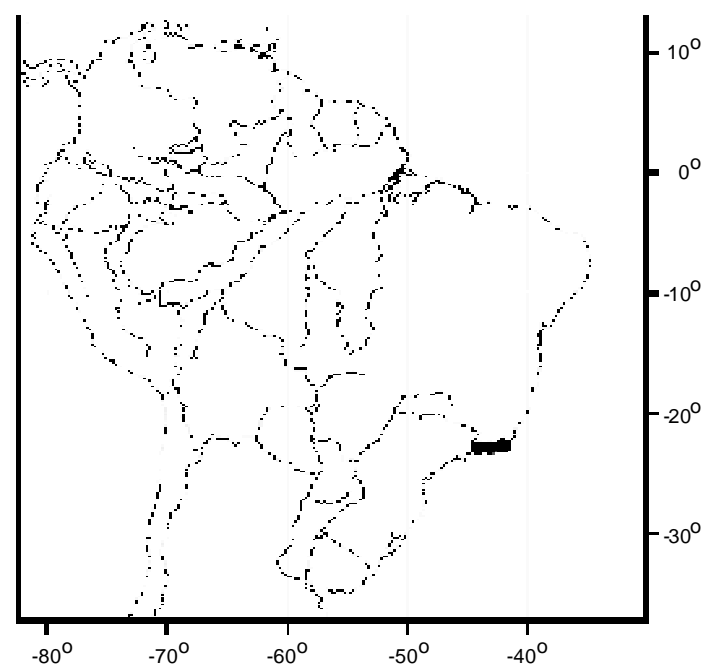

Figura 14 - Inga mendoncaei 
Domínio Atlântico, a exceção de Swartzia pilulifera, e têm distribuições restritas às floresta ombrófila densa e floresta estacional semidecidual do sudeste.

Uma síntese do conjunto dos padrões de distribuição (Fig. 15) e a correlação à preferên-cia de habitat das espécies de Leguminosae estudadas para a flora do PARNA Itatiaia mostrou que do total de espécies analisadas, $56 \%$ são generalistas e 44\% especialistas em formações do Domínio Atlântico (Tab. 2). Os padrões predominantes de distribuição das espécies generalistas são o neotropical, seguido do Brasil centro-oriental e o América do Sul ocidental-centro-oriental. Os táxons especialistas do Domínio Atlântico foram reconhecidos, principalmente, nos padrões: Brasil Atlântico nordeste-sudeste-sul,
Brasil Atlântico sudeste e Brasil Atlântico sudeste-sul.

O grupo de espécies especialistas revelou a predominância de táxons do domínio florestal atlântico (senso Oliveira-Filho \& Fontes 2000), destacando-se espécies características da flora da floresta ombrófila densa, seguidas da presença expressiva de elementos florísticos que também ocorrem nas florestas estacionais semidecíduas do sudeste. Tal fato corrobora a constatação das similaridades florísticas entre estas duas formações florestais no sudeste e a condição da flora arbórea da floresta semidecidual ser um sub-conjunto da flora das florestas ombrófilas (Oliveira-Filho \& Fontes 2000).

O conjunto de resultados obtidos mostra que a formação florestal montana e alto-

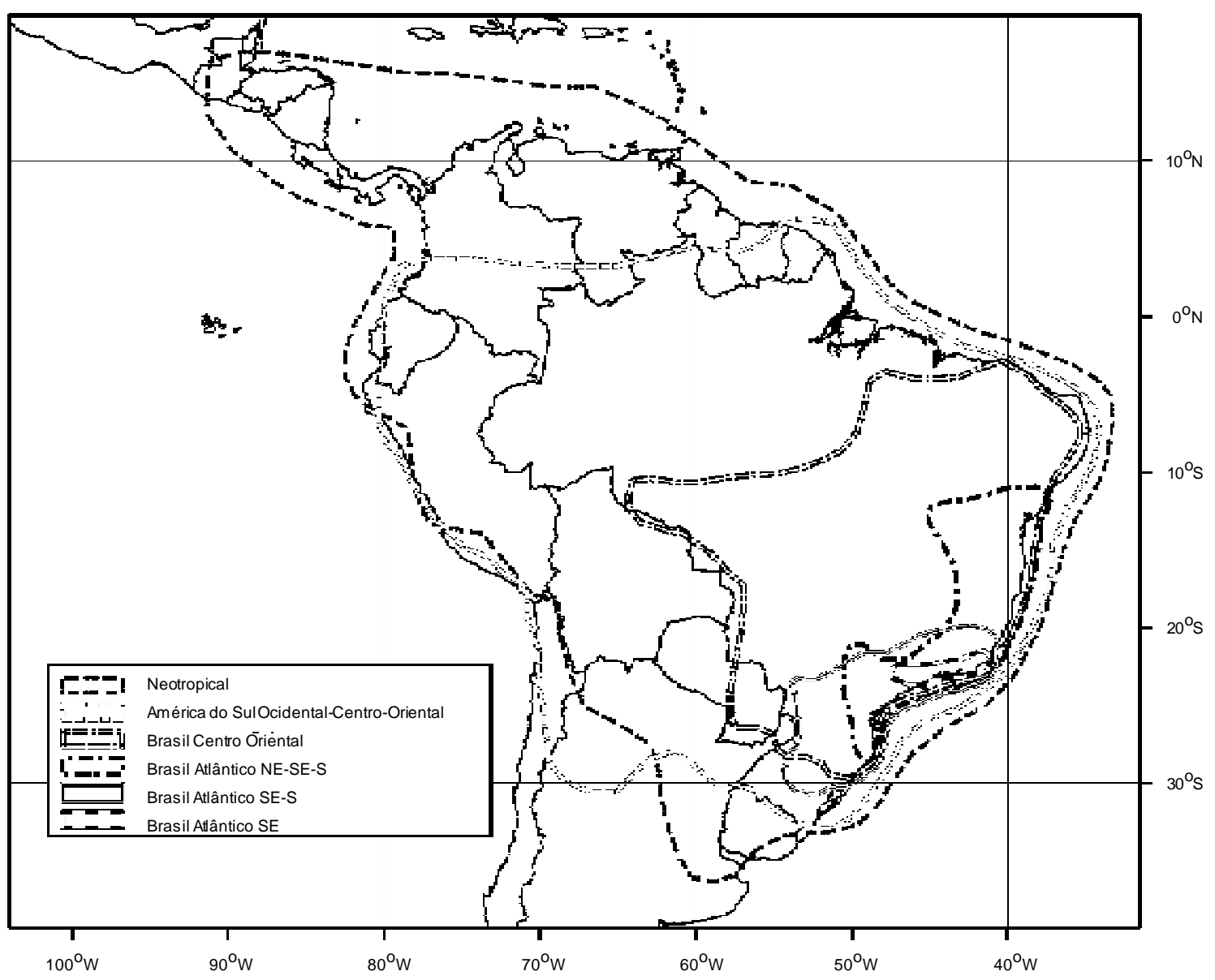

Figura 15 - Síntese de padrões de distribuição das Leguminosae do PARNA Itatiaia. 
montana do PARNA Itatiaia é um relevante núcleo de distribuição de Leguminosae no contexto das grandes cadeias montanhosas das Serra da Mantiqueira e da Serra do Mar, reforçando a condição do estado do Rio de Janeiro seja como centro de diversidade de espécies, centro de endemismo ou área provável de refúgio (Mori 1981 e 1989, Prance 1987, Prance 1994, Lima et al. 1997). Entretanto, resultados sobre a riqueza e diversidade das Leguminosas no Domínio Atlântico do sudete do Brasil, associados aos prováveis processos biogeográficos históricos e ecológicos aos quais os táxons foram e estão submetidos (Lima 2000), serão fundamentais para interpretações mais detalhadas sobre o conjunto florístico das Leguminosae na formação florestal do PARNA Itatiaia.

Estimula-se ainda que outras famílias botânicas que predominam na formação florestal do PARNA Itatiaia sejam estudadas e que este conjunto de resultados, associados aos diferentes aspectos que envolvem o maciço do Itatiaia (Safford 1999 a,b), promovam o avanço no conhecimento sobre a flora local.

\section{Agradecimentos}

À Dra. Gaziela Maciel Barroso, in memoriam, pelos valiosos ensinamentos no estudo de Sistemática de Leguminosae; à Dra. Dorothy Sue Dunn Araújo, Departamento de Ecologia da Universidade Federal do Rio de Janeiro, pela revisão do abstract. Ao bolsista da Fundação Botânica Margaret Mee/ Programa Mata Atlântica/Instituto de Pesquisas Jardim Botânico do Rio de Janeiro, pesquisador Sebastião da Silva Neto, pelo auxílio durante os trabalhos de campo; a Leonardo Gnattali de Mello Campos, bolsista do Centro de Informações e Serviços do Programa Mata Atlântica/JBRJ, pela elaboração dos mapas. Ao Parque Nacional do Itatiaia pelo apoio durante a realização do trabalho de campo e ao Instituto de Pesquisas Jardim Botânico do Rio de Janeiro, em especial ao Programa Mata Attântica, pelas condições de trabalho oferecidas e auxílio financeiro (convênio $\mathrm{n}^{\mathrm{O}}$ 610.4.025.02.3) através do patrocínio da Petrobrás.

\section{REFERÊNCIAS BibLIOGRÁfiCAS}

Ab'Sáber, A. N. 1977. Os domínios morfológicos da América do Sul. Geomorfologia 52: 1-23.

Altschul, S. von Reis. 1964. A taxonomic study of the genus Anadenanthera. Contributions from the Gray Herbarium of Harvard University 193: 1-65.

Barneby, R. C. 1991. Sensitivae censitae: a description of the genus Mimosa Linnaeus (Mimosaceae) in the New World. Memoirs of the New York Botanical Garden 65: 1-835.

Barneby, R. C. \& Grimes, J. 1996. Silk tree, Guanacaste, Monkey's earring: a generic system for the Synandrous Mimosaceae of the Americas. Part I. Abarema, Albizia, and Allies. Memoirs of the New York Botanical Garden 74(1): 1-292.

Barroso, G. M.; Peixoto, A. L.; Costa, C. G.; Ichaso, C. L. F.; Guimarães, E. F. \& Lima, H. C. 1984. Leguminosae. In: Sistematica de Angiospermas do Brasil. Universidade Federal de Viçosa. Viçosa. v. 2. Pp. 15-100.

Bernardes, L. M. C. 1952. Tipos de clima do Estado do Rio de Janeiro. Revista Brasileira de Geografia 14(1): 57-80.

Bigarella, J. J.; Andrade-Lima, D. \& Riehs, P. J. 1975. Considerações a respeito das mudanças paleoambientais na distribuição de algumas espécies vegetais e animais no Brasil. Anais da Academia Brasileira de Ciências 47(suplemento): 411-464.

Brade, A. C. 1956. A flora do Parque Nacional do Itatiaia. Boletim Parque Nacional do Itatiaia 5: 1-92.

Burkart, A. 1979. Leguminosas Mimosoideas. In: Reitz, R. Flora Ilustrada Catarinense, I parte, fascículo LEGU: 1-299.

Carvalho, A. M. 1997. A synopsis of the genus Dalbergia (Fabaceae: Dalbergieae) in Brazil. Brittonia 49(1): 87-109. 
Ducke, A. 1949. Notas sobre a Flora Neotropica II. As Leguminosas da Amazônia brasileira. Boletim Técnico do Instituto Agronômico do Norte 18: 1-248.

Dusén, P. 1903. Sur La flore de la Serra do Itatiaya au Brésil. Archivos do Museu Nacional do Rio de Janeiro 13: 1-119.

1955. Contribuições para a Flora do Itatiaia. Boletim Parque Nacional do Itatiaia 4: 9-91.

Fortunato, R. H. 1995. A new species of Collaea (Leguminosae: Papilionoideae: Phaseoleae: Diocleinae) from Brazil. Kew Bulletin 50(4): 795-99.

Garcia, R. 1989. Una Novedade en el genero Collaea (Fabaceae, Phaseoleae). Boletin de la Sociedad Argentina de Botanica 26(1-2): 136-137.

Gentry, A. H. 1995. Patterns of diversity and floristic composition in neotropical montane forests. In: Churchill, S. P.; Baslslev, H.; Forero, E. \& Luteyn J. L. 1993. Biodiversity and Conservation of Neotropical Montane Forests. Proceedings of the Neotropical Montane Forests Biodiversity and Conservation Symposium. The New York Botanical Garden, New York. Pp. 103-26.

Guedes-Bruni, R. R. 1998. Composição, estrutura e similaridade florística de dossel em seis unidades fisionômicas de Mata Atlântica no Rio de Janeiro. Tese de doutorado. Universidade de São Paulo, São Paulo.

Guedes-Bruni, R. R.; Morim, M. P.; Lima, H. C. \& Sylvestre L. S. 2002. Inventário florístico. In: Sylvestre, L. S. \& Rosa, M. M. T. (orgs.). Manual metodológico para estudos botânicos na Mata Atlântica. Seropédica, EDUR. Pp. 24-50.

IBAMA 2005. IBAMA Web [on line, 22/07] http://www.ibama.gov.br.

Irwin, H. S. \& Barneby, R. C. 1982. The American Cassiinae: a synoptical revision of Leguminosae Tribe Cassieae subtribe Cassiinae in the New World. Memoires of the New York Botanical Garden 35 (part 1-2): 1-1918.

Joly, C. A.; Aidar, M. P. M.; Klink, C. A.; Mcgrath, D. G.; Moreira, A. G.; Moutinho, P.; Nepstad, D. C.; Oliveira, A. A .; Pott, A .; Rodal, M. J. N. \& Sampaio, E. V. S. B. 1999. Evolution of the Brazilian phytogeography classification systems: implications for biodiversity conservation. Ciência e Cultura 51(5/6): 331-48.

Krukoff, B. A. \& Barneby, R. C. 1974. Conspectus of species of the genus Erythrina. Lloydia 37(3): 332-459.

Lavin, M. 1994. Origin, diversity and biogeography of neotropical Fabaceae. Proceedings of the VI Congreso Latinoamericano de Botánica. Monographs in Systematic Botany from Missouri Botanical Garden 68: 131-145.

Lee, Yin-Tse \& Langenheim, J. H. 1975. Systematics of the genus Hymenaea $\mathrm{L}$. (Leguminosae, Caesalpinioideae, Detariae). University of California Publications in Botany 69: 1-109.

Lewis, G. P. 1987. Legumes of Bahia. Royal Botanic Gardens. Kew. 369p.

Lewis, G. P. \& Lima, M. P. M. 1989/90. Pseudopiptadenia Rauschert no Brasil (Leguminosae-Mimosoideae). Arquivos do Jardim Botânico do Rio de Janeiro 30: 43-67.

Lewis, G. P. \& Schire, B. D. 2003. Leguminosae or Fabaceae? In: Klitgaard, B. B. \& Bruneau, A. (ed.). Advances in Legume Systematics Part 10. Royal Botanic Gardens, Kew. Pp. 1-3.

; Schrire, B.; Mackinder, B. \& Lock, M. 2005. Legumes of the world. Royal Botanic Gardens. Kew. 577p.

Lima, H. C. 2000. Leguminosas arbóreas da Mata Atlântica. Uma análise da riqueza, padrões de distribuição geográfica e similaridades florísticas em remanescentes florestais do estado do Rio de Janeiro. Tese de doutorado. Universidade Federal do Rio de Janeiro, Rio de Janeiro. 
Lima, H. C.; Correia, C. M. B. \& Farias, D. S. 1994. Leguminosae. In: Lima, M. P. M. \& Guedes-Bruni, R. R. (org.). Reserva Ecológica de Macaé de Cima, Nova Friburgo, RJ: Aspectos florísticos das espécies vasculares, v.1. Jardim Botânico do Rio de Janeiro. Pp. 167-228.

Lima, M. P. M.; Guedes-Bruni, R. R.; Sylvestre, L. S. \& Pessoa, S. V. A .1997. Padrões de distribuição geográfica das espécies vasculares da Reserva Ecológica de Macaé de Cima. In: Lima, H. C. de \& Guedes-Bruni, R. R. (eds.). Serra de Macaé de Cima: Diversidade Florística e Conservação em Mata Atlântica. Rio de Janeiro. Jardim Botânico do Rio de Janeiro. Pp.103-124.

Mansano, V. F. \& Tozzi, A. M. G. A. 1999. Distribuição geográfica, ambiente preferencial e centros de diversidade dos membros da tribo Swartzieae na região sudeste do Brasil. Revista Brasileira de Botânica 22 (2 - suplemento): 249-257. . 2001. Swartzia Schreb. (Leguminosae: Papilionoideae: Swartzieae): a taxonomic study of the Swartzia acutifolia complex including a new name and a new species from southeastern Brazil. Kew Bulletin 56(4): 917-929.

\& Lewis, G. P. 2004. A revision of the South American genus Zollernia Wied-Neuw. \& Nees (Leguminosae, Papilionoideae, Swartzieae). Kew Bulletin 59: 497-520.

Mendes Jr., L. O.; Antoniazzi, M.; Vieira, M. C. W. \& Susemibl, P. 1991 (coord.). Relatório Mantiqueira. FEDAPAM. São Paulo. 54p.

MA-IBDF (Ministério da Agricultura, Instituto Brasileiro de Desenvolvimento Florestal) - FBCN (Fundação Brasileira para a Conservação da Natureza). 1982. Plano de Manejo do Parque Nacional do Itatiaia. Brasília. 207p.

Mori, S. A.; Boom, B. M. \& Prance, G. T. 1981. Distribution patterns and conservation of easterns brazilian coastal forest tree. Brittonia 33(2): 233-245. 1989. Eastern, Extra-amazonian Brazil. In: Campbell, D. G. \& Hammond, H. D. Floristic inventory of tropical countries. New York, New York Botanical Garden. Pp. 428-454.

Morim, M. P. 2002. Leguminosae arbustivas e arbóreas do Parque Nacional do Itatiaia: abordagem florítico-taxonômica. Tese de doutorado. Universidade Federal do Rio de Janeiro, Rio de Janeiro.

Occhioni Martins, E. M. O. 1974. Stryphnodendron Mart. Leg. Mim. As espécies dos nordeste, sudeste e sul do Brasil II. Leandra 3-4(4-5): 53-60. 1981. Stryphnodendron Mart. (Leguminosae:Mimosoideae) com especial referência aos taxa amazônicos. Leandra 10-11:3-100.

Oliveira-Filho, A. T. \& Ratter, J. A. 1995. A study of the origin of central brazilian forests by the analysis of plant species distribution patterns. Edinburgh Journal of Botaniy 52(2): 141-194.

Oliveira-Filho, A. T. \& Fontes, M. A. L. 2000. Patterns of floristic differentiation among Atlantic Forests in Southeastern Brazil an the influence of climate. Biotropica 32(4b): 793-810.

Pennington, T. D. 1997. The Genus Inga Botany. Royal Botanic Gardens, Kew. Inglaterra. 844p.

Pennington, R. T. 2003. Monograph of Andira (Leguminosae-Papilionoideae). Systematic Botany mongraphs 64: 1-143.

Prado, D. E. \& Gibbs, P. E. 1993. Patterns of species distributions in the dry seasonal forests of South America. Annals of Missouri Botanical Garden 80: 902-27.

Prance, G. T. 1987. Biogeography of neotropical plantes. In: Whitmore, T. C. \& Prance, G. T. 1987. Biogeography and Quaternary History in Tropical America. Clarendon Press. Oxford. Pp. 46-65. 
1994. The use of phytogeographic data for conservation planning. Systematics and Conservation Evaluation 50: $145-63$.

Ribeiro, K. T. \& Medina, B. M. O. 2002. Estrutura, dinâmica e biogeografia das ilhas de vegetação sobre rocha do planalto do Itatiaia, RJ. Boletim do Parque Nacional do Itatiaia 10: 11-84.

Safford, H. D. 1999a. Brazilian Páramos I. An introduction to the physical environment and vegetation of the campos de altitude. Journal of Biogeography 26: 693-712. 1999b. Brazilian Páramos II. Macroand mesoclimate of the campos de altitude and affinites with high mountain climates of the tropical Andes and Costa Rica. Journal of Biogeography 26: 713-737.

Sartori, A. L. B. \& Tozzi, A. M. G. A. 1998. As espécies de Machaerium Pers. (Leguminosae Papilionoideae Dalbergieae) ocorrentes no estado de São Paulo. Revista Brasileira Botânica 21(3): 211-246. 2004. Revisão taxonômica de Myrocarpus Allemão (Leguminosae, Papilionoideae, Sophoreae). Acta Botânica Brasílica 18(3): 521-35.

Segadas-Vianna, F. 1965. Ecology of Itatiaia range, southeastern Brazil. I. Altidudinal zonation of the vegetation. Arquivos Museu Nacional Rio de Janeiro 53: 7 -30.

Segadas-Vianna, F. \& Dau, L. 1965. Ecology of Itatiaia range, southeastern Brazil. II.
Climates and altitudinal climatic zonation. Arquivos Museu Nacional Rio de Janeiro 53: 31-53.

Ururahy, J. C.; Collares, J. E. R.; Santos, M. M. \& Barreto, R. A. A. 1983. Vegetação. In: RADAMBRASIL. Folhas SF 23/24 Rio de Janeiro/Vitória. Levantamento dos Recursos Naturais 32: 553-623.

Vaz, A. S. F. \& Silva, D. C. P. 1995. Bauhinia (Leguminosae - Caesalpinioideae) da Reserva Florestal da Vista Chinesa, Rio de Janeiro. Albertoa 4(5): 53-60.

Vaz, A. S. F \& Tozzi 2003. Bauhinia ser. Cansenia (Leguminosae: Caesalpinioideae) no Brasil. Rodriguesia 54(83): 55-143.

Veloso, H. P.; Rangel Filho, A . L. R. \& Lima, J. C. A. 1991. Classificação da vegetação brasileira, adaptada a um sistema universal. Instituto Brasileiro de Geografia e Estatísitca. Rio de Janeiro. 116p.

Wojciechowski, M. F. 2003. Reconstructing the phylogeny of legumes (Leguminosae): an early $21^{\text {st }}$ century perspective. In: Klitgaard, B. B. \& Bruneau, A. (eds.). Advances in Legume Systematics Part 10. Royal Botanic Gardens, Kew. Pp. 5-35.

Wojciechowski, M. F.;Lavin, M. \& Sanderson, M. J. 2004. A phylogeny of Legumes (Leguminosae) basead on analysis of the plastid mat- $K$ gene resolves many wellsupported subclades within th family. American Journal of Botany 91(11): 18461862. 
